\title{
Production and Utilization of Amino Acid by Brewer's Yeast during Brewing Process: A Review
}

\author{
Igboanugo, E.U.* ${ }^{\circledR}$, Chukwura, E.N. \\ Department of Microbiology, Chukwuemeka Odumegwu Ojukwu University, Anambra State, Nigeria.
}

*Corresponding author's email: edwinuchechukwu@yahoo.com

\begin{abstract}
Conventional beer production involves four technological steps which are; malting, mashing, wort boiling and fermentation. Amino acids metabolism include the breakdown of protein that is usually initiated during malting but occurs largely during mashing in beer brewing process and the transamination reaction which occurs through the metabolism of yeast cells during the fermentation process. Brewer's yeasts are mostly part of the genus Saccharomyces. Ale yeasts belongs to the species Saccharomyces cerevisiae and lager yeasts to the species Saccharomyces uvarum or Saccharomyces pastorianus (an interspecies hybrid between Saccharomyces cerevisiae and Saccharomyces eubayanus). At the start of fermentation, only eight amino acids (Arginine, Aspartate, Asparagine, Glutamate, Glutamine, Lysine, Serine and Threonine) are readily available and are rapidly assimilated by the yeast cell from the wort and these amino acids are synthesized through the activities of two proteolytic enzymes which are; proteases and polypeptidases. The proteases work to breakdown the larger proteins into polypeptides while the polypeptidases work to provide the wort with pool of amino acids nutrient by breaking down polypeptides and this enhance the head retention of beer and reduces haze. The remaining twelve amino acids needed for normal growth and metabolism of the yeast are produced by the yeast itself through transamination reaction and amination of organic acid with ammonia present in the cell. Amino acids also play a major role in the formation of flavor compounds in beer and consequently improve the organolytic quality of the final product (beer). The article covers the importance of amino acids production, utilization and its effects on brewer's yeast during wort fermentation and beer production.
\end{abstract}

Review Article

Received: 30th Sept., 2017

Accepted: 21st Oct., 2017

Published: 23 ${ }^{\text {rd }}$ Oct., 2017.

Keywords:

Amino acids;

Fermentation;

Enzymes;

Brewer's yeast;

Transamination

\section{INTRODUCTION}

$\mathrm{B}$ arley has been widely used for the production of malt in the brewing industry. Malt is the main raw material indispensable for beer brewing. The fermentability of malt wort is dependent on an adequate supply of the essential nutrients required by yeast. The amino acid content is an important malt parameter to the yeast growth and metabolism in malt wort. To increase brewing fermentability and efficiency, malts with high levels of free amino nitrogen and amino acids are essential (Cong et al., 2010). Amino acids can be defined as the building blocks, monomers or precursors of proteins. Amino acid is also any of organic compounds containing one or more amino groups $\left(-\mathrm{NH}_{2}\right)$ and one or more carboxyl groups (-COOH) and a distinctive side chain, especially any of the 20 amino acids that are link together to form proteins (American Heritage Dictionary of English Language, 2011). There are three functional groups present in the structure of amino acid, and they include; alpha amino groups $\left(-\mathrm{NH}_{2}-\right), \mathrm{R}-$ group (the side chain) and acid carboxyl group (- $\mathrm{COOH}-$ ). For all amino acids the alpha amino group and the carboxyl group must be the same, the difference is determined from the R-group, the side chain (Lukong et al., 2007). Barley which is used in beer production has a nutritional composition of carbohydrate $78.30 \mathrm{~g}$, protein $10.28 \mathrm{~g}$, fat $1.84 \mathrm{~g}$, fibre $7.10 \mathrm{~g}$ etc. During 
kilning, Maillard reaction occurs between amino acids and sugars, generating melanoid that gives beer color and flavor (Samaras et al., 2005). Amino acid content plays a crucial role in yeast nutrition. The fact that the increase in amino acid level is mainly due to the respiration of barley during malting is generally recognized. It has been speculated that different malts produced by different malting programs or barley varieties, contain various amino acids at different levels. Many different types of low malt beer were brewed around the world. In China, the malt adjuncts of rice, sugar syrups and maize starch are used in most of the breweries. To increase the amino acid contents of barely is absolutely necessary. The amino acid levels will affect the fermentability because they are essential yeast nutrients. The difference in amino acid contents will also affect beer flavors (Perpète et al., 2005)

The barley undergoes enzymatic reaction to breakdown carbohydrates into simple sugars and proteins into amino acids. Brewer's yeast is used during fermentation to produce ethanol and carbondioxide $\left(\mathrm{CO}_{2}\right)$, but ethanol and $\mathrm{CO}_{2}$ make little contribution to beer flavour. The main contribution of sugar metabolism to flavour is the production of a range of esters. Since both acetic acid and ethanol are formed during fermentation, ethyl acetate would be formed by direct esterification reaction.

Active yeast growth requires nitrogen metabolism mainly in the form of amino acids for synthesis of protein and other nitrogenous components of cells. Amino acids, like sugars do not permeate freely into the cells by simple diffusion rather yeast cell takes up amino acids from the wort, across the cell membrane and into the cytoplasm, through active transport. Proteins are a very important class of organic components in beer. They are long chains or polymers with large molecular weight composed from amino acids connected to each other via peptide bonds. Quality and sustainability of beer depends on its protein content. Proteins play a very important role in many stages of brewing process. They are essential in the malt and wort production, also have a direct impact on the consistency and the formation of beer foam. This means the protein content in malt affect the quality of the finished product (Kamburi and Pinguli, 2017). The free Amino Nitrogen (FAN) content of wort prescribes efficient yeast cell growth and fermentation performance. Free amino nitrogen consist of the individual amino acids, small peptides and ammonia ions formed during malting, the relative amount vary. Free Amino Nitrogen (FAN) is an essential component of yeast nutrition in brewing as it promotes proper yeast growth and efficiency (Good et al., 2003; Lekka et al., 2007). It also plays a role in the maintenance of foam stability (Good et al., 2003). Free amino nitrogen values of malts increase with increased germination time due to more extensive protein hydrolysis, hydrolyzed by proteases, barley proteins are broken down into low molecular weight peptides and amino acids, which serve as nutrients for embryo secretion and new protein synthesis (Klose et al., 2008). Most beer is flavoured with hops, which add betterness and act as a natural preservative, though other flavourings such as herbs or fruit may occasionally be included. Beer is the product of alcoholic fermentation of worts from malted cereals, unmalted cereals and sugar sources (Mathias et al., 2014).

\section{BASIC INGREDIENTS IN BEER PRODUCTION}

The key ingredients utilized for the production of most beers are barley, water, hops and yeast. However, alternative source of extract (adjuncts) may also be used (e.g. rich starches, hydrolysed corn syrup, sucrose or sorghum) either to introduce necessary characteristics to the final product or to reduce the cost (Boulton and Quain, 2003; Briggs et al., 2004). Adjuncts may replace a proportion of the fermentable carbohydrates provided that they do not negatively affect product quality and in particular flavor. The mineral, ionic content and the $\mathrm{pH}$ of the water have profound effects on the type of beer produced. The water may be 'burtonized' by the addition of calcium sulfate (gypsum), acid can also be added, the water may be decarbonated by boiling, or improved by ion exchange (Nduka,2007). During fermentation, yeast cells degrade sugar into alcohol and carbondioxide. Brewer's yeast also require amino acids to build up proteins and enzymes within the cell. Brewer's yeast cells provided with an appropriate source of carbon and ammonium can synthesize all L-amino acids used in protein synthesis. Ammonia is incorporated during the formation of glutamate from $\alpha$ ketoglutarate by NADPH-dependent glutamate dehydrogenase (GDH1), and glutamine from glutamate by glutamine synthetase (Magasanik, 2003). The families of amino acids derived from a common molecule are readily identifiable and include the glutamate family (glutamate, glutamine, arginine, proline, and lysine); the aromatic family (phenylalanine, tyrosine, and tryptophan); the serine family (serine, glycine, cysteine, and methionine); the aspartate family (aspartate, asparagine, threonine, and the sulfur containing amino acids cysteine and methionine); and the pyruvate family (alanine and the branched amino acids valine, leucine, and isoleucine). The importance of glutamate and glutamine, and consequently the central core reactions in nitrogen metabolism, becomes apparent by highlighting their involvement in transamination reactions required in the synthesis of each amino acid (Magasanik and Kaiser, 2002). If malting and wort production are properly done, amino acids would be made very much available in the wort. Some amino acids are more easily absorbed by the brewer's yeast than others.

\section{AMINO ACIDS METABOLISM DURING BREWING}

Amino acid metabolism is the term that describes the degree of breakdown of protein which results in production of different amino acids (amino acid-anabolism) and utilization of amino acid in the production of ammonium and other nitrogenous compounds when needed in by the yeast cell (amino acid catabolism). Malted barley also contains a lot of amino acid chains which form the simple proteins needed by the germinating plant. In the wort, these proteins are instead utilized by the yeast for their growth and development. Most wort proteins, including some enzymes like the amylases are not soluble until the mash reaches temperatures associated with the protein rest $\left(45^{\circ} \mathrm{C}-55^{\circ} \mathrm{C}\right)$. The two main proteolytic enzymes responsible are protease and peptidase. Protease works to break up the larger proteins which enhances the head retention of beer and reduces haze while Peptidase works to provide the wort with amino acids nutrients that will be used by the yeast. Brewer's yeast absorb most of the amino acids they need directly from the wort. They are also able to 
produce many of the amino acids needed for growth from other, more easily absorbed amino acids, using transamination reactions. Yeast cell removes the amino group from an amino acid and attach it to an organic acid already inside the cell, creating a new amino acid. This leaves the former amino acid without an amino group and now is an oxo-acid which is decarbonated into an aldehyde by the loss of $\mathrm{CO}_{2}$ molecule, and then reduced to a higher alcohol. A particular amino acid will eventually produce a particular higher alcohol following transamination and reduction. The formation of higher alcohols reduces the potential toxicity of the oxo-acids and at the same time regenerates important cofactors needed for the reactions. The presence of surplus of a particular amino acid in wort may inhibit the formation of the corresponding higher alcohol; likewise, a shortage of a particular amino acid in the wort will lead to underproduction of its corresponding higher alcohol.

The faster yeast grow, the more rapid is the production of amino acids and the more oxo-acids and hence higher alcohols are produced. Higher fermentation temperatures encourage yeast growth, so if the temperature is increased then amino acid synthesis increases. When amino acids are in short supply in the wort, then yeast will use the transamination reactions to produce the required amino acids. Too few amino acids in wort will force yeast to manufacture rather than directly utilize amino acids, which will result in an increase in higher alcohol production. Valine is a classic example. Valine is an amino acid that yeast can either produce autonomously, or assimilate from the wort. An intermediate compound in valine production is acetolactate (Fig. 1), not all of the acetolactate produced will be converted to valine; some will leak out of the cell and into the beer. This acetolactate is then chemically (not enzymatically) converted to diacetyl in the beer. The chemical reaction is an oxidation, and high fermentation temperature favours this reaction, other factors that will increase diacetyl production in this phase are insufficient nutrients (e.g. the amino acid; valine), which forces yeast to manufacture their own. For example, the more valine yeast produce, the more acetolactate intermediate is required, and hence the more diacetyl made. There is also an apparent strain specific phenomena occurring, because given the same conditions, different strains will produce different levels of diacetyl.

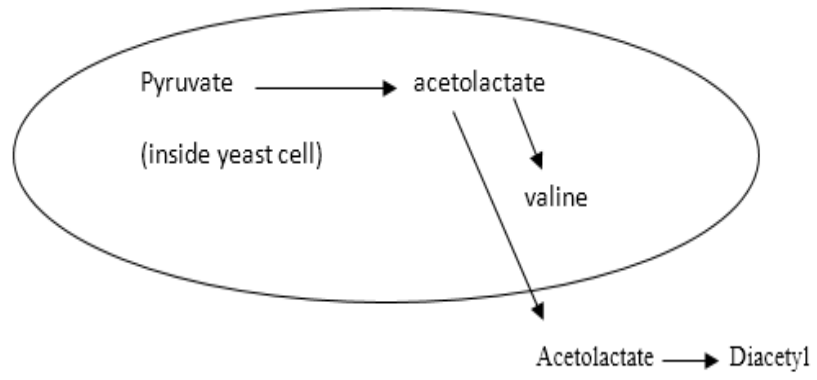

Figure 1: Production of valine.

Source: White, (2001).

\section{FLAVOUR FORMATION IN BEER BY AMINO ACID METABOLIC BY-PRODUCT}

The characteristic flavour and aroma of any beer is, in large part, determined by the yeast strain employed and the wort composition. In addition, properties such as flocculation, wort fermentation ability (including the uptake of wort sugars, amino acids, and peptides), ethanol and osmotic pressure tolerance together with oxygen requirements have a critical impact on fermentation performance (Graham, 2016). During fermentation, yeast cells degrade sugars into alcohol and carbon dioxide, while other minor pathways are also active and yeast produces other compounds while a beer ferments. The flavour and aroma of beer is very complex, being derived from a vast array of components that arise from a number of sources. Not only do malt, hops, and water has an impact on flavour, so does the biosynthesis of yeast, which forms by-products during fermentation and conditioning through the amino acids reactions. The most notable of these by-products are, of course, ethanol and carbondioxide; but in addition, a large number of other flavour compounds such as esters, higher alcohols, diacetyl, aldehydes, sulphur compounds and acid, of which some flavour compounds named above are formed through amino acid reaction during transamination.

\section{Higher alcohols}

Higher alcohols (Fig. 2) are very important beer flavour. They are essentially more complex forms of alcohol than the simple neutral flavored ethanol that accounts for most of the alcohol in beer. Ethanol is a two carbon molecule whose formula is or solvent like character to beer. The balance between the levels of higher alcohols and esters is an important factor in determining the beers drinkability.

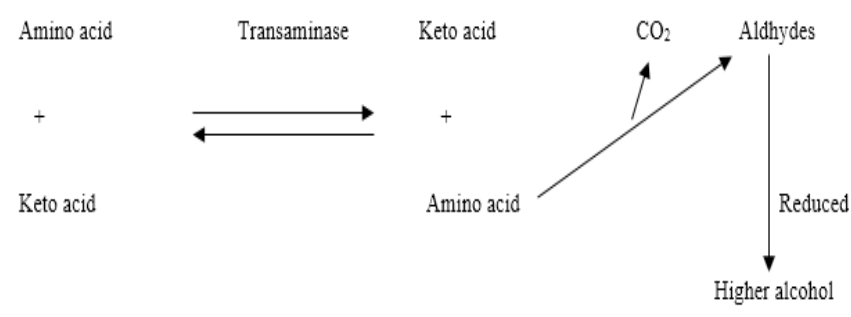

Figure 2: Production of higher alcohols in beer.

Source: Annan et al., (2002).

\section{Esters}

Esters are considered the most important aroma compounds in beer. They make up the largest family of beer aroma compounds and in general important a "fruity" character to beer. Under fermentation conditions, the most common ester produced during fermentation is ethyl acetate. Ester production (Fig. 3) is increased by increasing the gravity above $18^{\circ} \mathrm{P}$, increasing the attenuation limit, restricting wort aeration, restricting yeast growth, increasing fermentation temperature and decreased motion during fermentation. Conversely, ester production is decreased by lower gravity, increased wort aeration, decreased attenuation unit, decreasing fermentation temperature, increased pressure during primary fermentation and under pitch. However, reacting an organic acid with an alcohol by the yeast during 
fermentation forms these compounds. Example, methanol is reacting with butyric acid, which smells like vomit to produce methyl butyrate, which smells like apples or pineapples. Enzymes called ester transferase catalyze these reactions within the yeast cells that are ultimately secreted from the yeast into the wort.

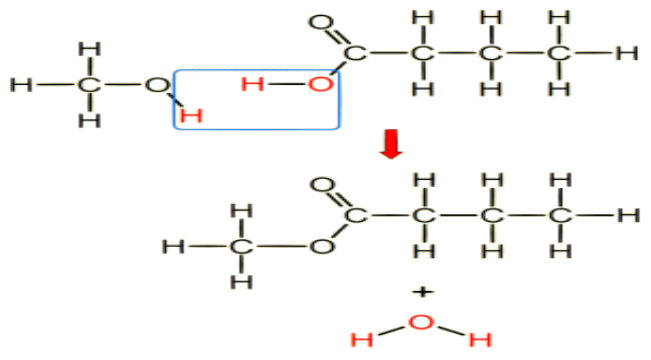

Organic acid + Alcohol $\longrightarrow$ Ester + Water

Figure 3: Production of esters in beer.

\section{Sulphur compounds}

Sulphur compounds are responsible for some of the most aromatic beer flavours. Some of the most aromatic aroma compounds have minute flavour threshold and so, even though they are present in small quantities, they dramatically affect the beer's flavours. Sulphur compounds have their origins in the ingredients we use sulfate, sulfite and sulfide ions in the water and sulfur compounds present in malt and hops, can all lead to sulfur flavours in the beer.

\section{Diacetyl}

Diacetyl (Fig. 4) is the compound responsible for buttery or butterscotch flavours that sometimes arise in beer. Diacetyl and 2, 3-pentanedione as ketones and diacetyl is usually called 2, 3-butanedione in the literature, sometimes these two ketones are grouped and reported as the vicinal diketone (VDK) content of beer. The study of diacetyl and beer began with pasteur's fundamental work in the 1870's. Using microscopy, Pasteur found that what we know today as lactic acid bacteria were responsible for many off flavours in beer.

Yeast Produce $\quad$ Acetolactate $\longrightarrow$ Valine
\[ \begin{array}{l}\text { High temperature/ } \\ \text { Oxidation occur. }\end{array} \]
Diacetyl

Figure 4: Production of Diacetyl.

Source: Petersen et al., (2004).

\section{CONCLUSION}

The amino acid metabolism in beer which include both the synthesis and utilization of amino acids in the wort is carried out by the metabolic activities inside the yeast cell. The amino acids that are readily available in wort at the start of fermentation are only eight in number, whereas the yeast cell needs the whole twenty amino acids for its normal growth and metabolism, these remaining twelve amino acids are made available by yeast itself through transamination reaction and amination of organic acids present in the cells. These two reactions also produce metabolites that can be used in the synthesis of flavoring compounds found in beer such as Higher alcohols, Diacetyl, Esters, and sulphur compounds.

\section{REFERENCES}

Annan, N.T., Poll, L., Sefa-Dedeh, S., Plahar,W.A. and Jakobsen, M. (2002). Volatile compounds produced by lactobacillus fermentum, Saccharomyces cerevisiea and Candida krusei in single starter culture fermentations of Ghanaian Maize dough. Journa of Applied Microbiology. 94:462-474. https://doi.org/10.1046/j.1365-2672.2003.01852.x.

Bamforth, C. (2003). Beer: Tap into the art and science of brewing. New York: Oxford University Press.

Boulton, C. A. and Quain, D. (2003). Brewing yeast and fermentation. Oxford: Blackwell Science.

Briggs, D.E., Boulton, C.A, Brookes, P.A., and Stevens, R., (2004). Brewing Science and Practice, Woodhead publishing.Cambridge.UK. pp. $10-606$. https://doi.org/10.1201/9780203024195.

Cong, N., Changlu, W., Guangtian, Z., Fangjun, D. and Mengmeng, H. (2010). Effects of malting conditions on the amino acid compositions of final malt. African Journal of Biotechnology, 9(53): 9018 - 9025.

Graham, G. S. (2016). Saccharomyces species in the Production of Beer. The International Centre for Brewing and Distilling, Heriot-Watt University, Riccarton, Edinburgh EH14 4AS, Scotland, UK. pp. 1-4.

Kamburi, T. and Pinguli, L. (2017). Impact of malt protein parameters on brewing process optimization. Albanian Journal of Agricultural Sciences, special edition, pp.477478.

Klose, C., Schehl, B., and Arendt, E. (2008). Changes in protein and amino acid composition during malting-A comparison of barley and oats, World Brew. Congr. Pro., August 2-6, Honolulu, Hawaii, USA. pp.158.

Lekkas, C., Stewart, G. G., Hill, A. E., Taidi, B. and Hodgson, J. (2007). Elucidation of the role of nitrogeneous wort components in yeast fermentation. Journal of Institute of Brewing, 113: $3-11$ https://doi.org/10.1002/j.2050-0416.2007.tb00249.x.

Lukong, B.C., Nwuke, C.P., Mbuh, A.F. and Fobella, A.D. (2007). Introduction to protein Science. Kriscona Press, Owerri, pp. $34-42$.

Magasanik, B. (2003). Ammonia assimilation by Saccharomyces cerevisiae. Eukaryot. Cell, 2: 827-829. https://doi.org/10.1128/EC.2.5.827-829.2003.

Magasanik, B., and C. A. Kaiser, (2002). Nitrogen regulation in Saccharomyces cerevisiae. Gene 290: 1-18. https://doi.org/10.1016/S0378-1119(02)00558-9.

Mathias, T.R., Moretzsohn de Mello P.P., and Servulo, E.F., (2014). Nitrogen compounds in brewing wort and beer: A review. Journal of Brewing and Distilling, 5(2):10-17.

Nduka, O., (2007). Mordern Industrial Microbiology and Biotechnology.An Imprint of Edenbrigde Ltd. British Isles. Enfield New Hampshire USA. pp 237-257.

Peddie, H.A.B. (1998). Ester formation in brewery fermentation. . Journal of Institute of Brewing, 96: 327-331. https://doi.org/10.1002/j.2050-0416.1990.tb01039.x.

Petersen, E., Margaritis, A., Stewart, R., Pilkington, P., and Mensour, N. (2004). The effects of wort valine 
concentration on the total diacetyl profile and levels late in batch fermentations with brewing yeast. Saccharomyces carlsbergensis. Journal of American Society of Brewing Chemist, 62: 131-139.

Perpète, P., Santos, G., Bodart, E., and Collin, S. (2005). Uptake of amino acids during beer production: the concept of a critical time value. Journal of American Society of Brewing Chemist, 63: 23 - 27.

Samaras, T. S., Camburn, P. A., Chandra, S. X., Gordon, M. H., and Ames J. M. (2005). Antioxidant Properties of Kilned and Roasted Malts. Journal of Agriculture and Food Chemist, 53: 8068 - 8074 . https://doi.org/10.1021/jf051410f.

Smith, M. B. and March, J. (2001). J. Advanced Organic Chemistry: Reactions, Mechanisms, and Structure, 5th ed. Wiley, pp. 503.
White, C. (2001). Diacetyl Time Line -white Labs [Online] available: www.whitelabs.com/.../Diacetyl.

\section{$\underline{\text { How to cite this article }}$}

Igboanugo, E.U. and Chukwura, E.N. (2017). Production and Utilization of Amino Acid by Brewer's Yeast during Brewing Process: A Review. Tropical Journal of Applied Natural Sciences, 2(1): 117-121.

Doi: https://doi.org/10.25240/TJANS.2017.2.1.21. 